\title{
Chave de identificação dendrológica das espécies mais comuns de uma área de Cerrado Sensu Stricto, Gurupi, Tocantins
}

\author{
Key of dendrological identification of the most common species of a Cerrado Sensu Stricto \\ area, Gurupi, Tocantins state
}

\author{
Jacqueline Bonfim e Cândido', Rodney Haulien Oliveira Viana ${ }^{\mathrm{II}}$, Israel Gomes Morais ${ }^{\mathrm{III}}$, \\ Marcos Vinicius de Melo Amorim ${ }^{\mathrm{III}}$, Priscila Bezerra de Souza ${ }^{\mathrm{IV}}$
}

\begin{abstract}
Resumo
Estudos com chave de identificação dendrológica da flora arbustivo-arbórea do Cerrado no Estado do Tocantins ainda são escassos ou incipientes, promovendo, assim, uma lacuna de informações técnicas e científicas. Portanto, esta pesquisa visa respaldar o estabelecimento de prioridades para futuras estratégias de conservação e planos de manejo de espécies botânicas do Cerrado. Diante do contexto, objetivou-se elaborar uma chave dicotômica, baseada em caracteres vegetativos das espécies arbustivo-arbórea de uma área de cerrado sensu stricto em Gurupi - TO. Foram alocadas, sistematicamente, cinco parcelas permanentes de $20 \times 50 \mathrm{~m}$, ou seja, $1.000 \mathrm{~m}^{2}$ cada, sendo as mesmas distanciadas $10 \mathrm{~m}$ entre si. Amostraram-se todos os indivíduos arbustivo-arbóreos com circunferência a $1,30 \mathrm{~m}$ do solo (CAP) maior ou igual a $10 \mathrm{~cm}$. Os materiais botânicos das espécies foram herborizados seguindo as técnicas convencionais. Para a elaboração da chave de identificação, foi realizada uma seleção dentre as 106 espécies amostradas, considerando apenas as espécies que possuíam número de indivíduos maior ou igual a cinco, desta forma, foram selecionadas 54 espécies. Cabe ressaltar que essa seleção teve como objetivo incluir apenas as espécies de maior recorrência no cerrado sensu stricto, com a finalidade de viabilizar a funcionalidade da chave. A chave de identificação baseada em caracteres vegetativos foi composta por 54 espécies arbustivo-arbóreas de eudicotiledôneas e angiospermas basais, distribuídas em 47 gêneros, incluídos em 26 famílias botânicas. A confecção da chave de identificação dendrológica demonstrou-se uma ferramenta funcional, ou seja, permitiu uma rápida e fácil identificação das espécies vegetais amostradas.
\end{abstract}

Palavras-chave: Chave dicotômica; Dendrologia; Levantamento florístico

\begin{abstract}
Studies with key dendrological identification are still scarce or incipient, thus promoting a lack of technical and scientific information. Establishment of priorities for future conservation strategies and management plans for Cerrado botanical species. In view of the context, the objective was to elaborate a dichotomous key, based on vegetative characteristics of the shrub-tree species of an area of cerrado sensu stricto, Gurupi-TO state. Five permanent plots of $20 \times 50 \mathrm{~m}$, or $1000 \mathrm{~m}^{2}$ each, were systematically allocated, $10 \mathrm{~m}$ apart. All shrub-arboreal individuals, with circumference at $1.30 \mathrm{~m}$ of soil (CAP) greater than or equal to $10 \mathrm{~cm}$ were sampled. The botanical materials of the species, were herbalised following conventional techniques. For the elaboration of the identification key, a selection was made among the 106 species sampled, considering only the species that had a number of individuals greater or equal to 5 , in this way 54 species were selected. It should be emphasized that this selection had as objective to include only the species with the greatest recurrence in the cerrado sensu stricto, in order to make the key functionality viable. The identification key based on vegetative characters was composed of 54 shrub-tree species of eudicotiledonias and basal angiosperms, distributed in 47 genera included in 26 botanical families. The preparation of the dendrological identification key was shown to be a functional tool, that is, it allowed a quick and easy identification of the sampled vegetable species.
\end{abstract}

Keywords: Dichotomous key; Dendrology; Floristic survey

\footnotetext{
I Bióloga, Doutoranda em Biologia Vegetal, Universidade Federal de Pernambuco, Centro de Biociências, Departamento de Botânica, Av. Professor Moraes Rego, 1235, Cidade Universitária, CEP 50670-901,Recife (PE), Brasil. jacqueline.bonfm@hotmail.com (ORCID: 00000003-1092-0444)

II Biólogo, Dr., Professor do Curso de Ciências Biológicas, Universidade Federal do Tocantins, campus de Porto Nacional, Rua 03, Quadra 17, Lote 11, s/n, Setor Jardim dos Ipês, CEP 77500-000, Porto Nacional (TO), Brasil. rodney@mail.uft.edu.br (ORCID: 0000-0001-9418-1356)

III Engenheiro Florestal, Universidade Federal do Tocantins, campus de Gurupi, Rua Badejós, Chácaras 69 e 72, CEP 77402-970, Gurupi (TO), Brasil. israel.mrs@gmail.com (ORCID: 0000-0002-5251-7437)/marcosmvm17@hotmail.com (ORCID: 0000-0002-7309-3629)

IV Bióloga, Dra ., Professora do Curso de Engenharia Florestal e do Programa de Pós-Graduação em Ciências Florestais e Ambientais, Universidade Federal do Tocantins, campus de Gurupi, rua Badejós, Chácaras 69 e 72, CEP 77402-970, Gurupi (TO), Brasil. priscilauft@uft.edu.br(ORCID: 0000-0003-4602-3139)
} 


\section{Introdução}

O Cerrado é uma região de savana tropical da América do Sul, incluindo grande parte do Brasil Central, parte do nordeste do Paraguai e leste da Bolívia, sendo o segundo domínio brasileiro em extensão. O Cerrado ocupa aproximadamente $22 \%$ do território brasileiro, em uma área total estimada de 2.036 .448 $\mathrm{km}^{2}$ (BRASIL, 2014).

Em função de sua extensão territorial, o Cerrado compreende um mosaico de vários tipos vegetacionais. Em suas formações vegetais são encontradas desde vegetações campestres com predomínio de gramíneas, até as matas de galeria, formadas por três estratos arbóreos distintos, com complexidade estrutural típica das florestas tropicais (BUTTLER et al., 2012).

Essa diversidade de fitofisionomias é resultante da diversidade de solos, de topografia (altitudes variáveis de 200 até $1.600 \mathrm{~m}$ ) e de climas que ocorrem nessa região do Brasil Central (BRASIL, 2014). A alta diversidade de ambientes é refletida em uma elevada riqueza da flora, totalizando 12.356 espécies que ocorrem espontaneamente, sendo que aproximadamente $44 \%$ da sua flora é endêmica (MENDONÇA et al., 2008).

O Tocantins é um dos estados brasileiros com maior área coberta pelo bioma Cerrado (182.640 $\mathrm{km}^{2}$ ). Cerca de $72 \%$ de cobertura com vegetação nativa encontra-se preservada no estado, constituindo um dos maiores remanescentes desse bioma (BRASIL, 2015).

Entretanto, as formações savânicas, nas quais estão inseridas as áreas de cerrado sensu stricto geralmente ocupam, terrenos planos de solos profundos ideais à agricultura mecanizada que propicia a conversão de áreas naturais em lavouras e pastagens. Resultado disso, é que as formações savânicas perderam 64 milhões de hectares (SANO et al., 2007). Isso representa 47,84\% de sua cobertura vegetal original. Tal cenário é a maior taxa de desmatamento anual dentre todos os biomas brasileiros, liderados pelos estados do Maranhão, Bahia e Tocantins (SANO et al., 2007; FERREIRA et al., 2017).

Diante disso, o conhecimento da diversidade florística do cerrado sensu stricto é de fundamental importância para compreender a estrutura dessas comunidades. Estes estudos auxiliam na detecção de padrões de dominância de certas espécies, bem como, a importância das relações ecológicas na manutenção das comunidades. Isso é base na elaboração de programas de monitoramento, controle e conservação dos remanescentes ainda preservados. Dessa forma, os sistematas dispõem de várias ferramentas, sendo as chaves dicotômicas as mais importantes dentre elas (JUDD et al., 2009). A elaboração de chaves para identificação, tendo como base características morfológicas vegetativas, é menos utilizada quando comparada com as chaves que utilizam os caracteres florais, porém, diversos autores passaram a utilizar parâmetros dendrológicos em seus trabalhos (SILVA JÚNIOR; PEREIRA, 2009; URBANETZ; TAMASHIRO; KINOSHITA, 2010; PESTANA; ALVES; SARTORI, 2011; SILVA JÚNIOR, 2012; TEIXEIRA, 2015).

Isso ocorre porque a dendrologia se baseia em características macromorfológicas, fáceis de serem observadas. Assim, as chaves de identificação dendrológica permitem uma rápida individualização desses caracteres, facilitando e agilizando o trabalho de reconhecimento em campo de determinada espécie.

Segundo Rejmanek e Brewer (2001), chaves dicotômicas de identificação de espécies parecem ser a maneira mais eficiente para a determinação de espécies em pequenas áreas.

Estudos com chave de identificação dendrológica da flora arbustivo-arbórea no Estado do Tocantins são inexistentes ou incipientes, sendo conhecidos somente estudos fitossociológicos para a região (SANTOS; LÓLIS, 2007; PEDREIRA et al., 2011; HAIDAR et al., 2013, LEMOS, 2013; MEDEIROS; WALTER, 2012; FERREIRA et al., 2015; 2017), que suprem a lacuna de informações técnicas e científicas sobre o Cerrado no Estado. Portanto, o presente estudo visa contribuir com a identificação de algumas espécies recorrentes em uma área de Cerrado e respaldar futuras estratégias de conservação e planos de manejo de espécies botânicas do Domínio.

Perante a necessidade de ampliar informações sobre a vegetação arbustivo-arbórea independentemente do período de floração e/ou frutificação das espécies mais comuns de área de cerrado sensu stricto, Gurupi - TO, objetivou-se elaborar uma chave dicotômica, baseada em caracteres vegetativos das espécies com maior densidade de indivíduos. 


\section{Material e Métodos}

Caracterização da área de estudo

O estudo foi desenvolvido numa área de cerrado sensu stricto em transição com uma área florestal cerradão inserida na Reserva Legal da Fazenda Experimental da UFT, campus de Gurupi - TO, sob as coordenadas UTM 1146'21.5”'S 49॰03'27.7’'W (Figura 1).

Figura 1 - Mapa do fragmento de cerrado sensu stricto e a área de estudo inserido na Reserva Legal da Fazenda Experimental da UFT, campus de Gurupi - TO.

Figure 1 - Map of the cerrado sensu stricto fragment and the study area inserted in the Legal Reserve of the Experimental Farm of UFT, campus of Gurupi - TO state.

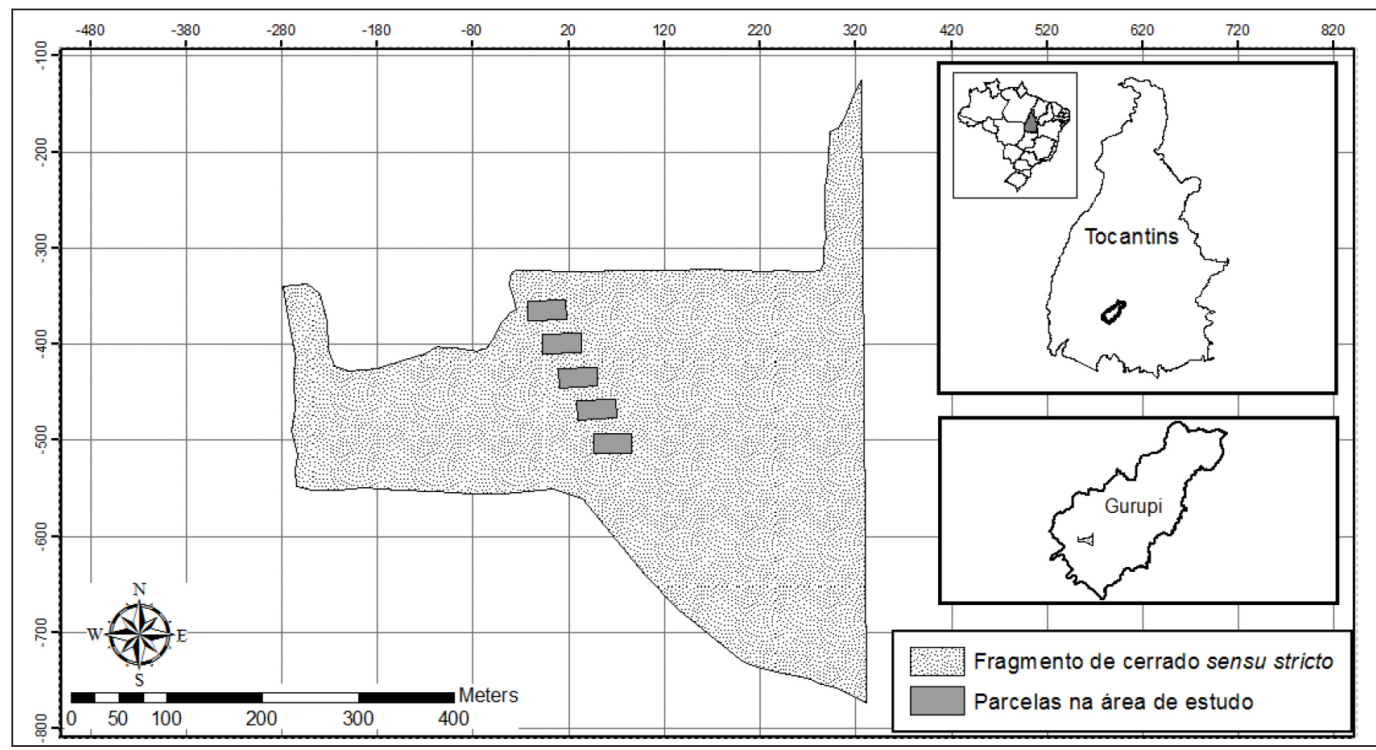

A Fazenda Experimental localiza-se próximo ao campus universitário de Gurupi e possui 138 ha de área total, sendo 38 ha de Reserva Legal com vegetação remanescente do domínio Cerrado, fisionomia caracterizada por cerrado sensu stricto, com presença de árvores baixas, inclinadas, tortuosas, com ramificações irregulares e retorcidas, geralmente apresentando evidências de queimadas. Os arbustos e subarbustos encontram-se espalhados, com algumas espécies apresentando órgãos subterrâneos perenes (xilopódeos), que permite a rebrota após a queima ou corte (RIBEIRO; WALTER, 2008).

O clima no Estado segundo Köppen é do tipo AW, definido como tropical úmido possuindo uma estação chuvosa no período de verão e uma seca no inverno. A precipitação varia entre $1.500 \mathrm{~mm}$ a 1.600 $\mathrm{mm}$, enquanto a temperatura média anual encontra-se entre $22^{\circ} \mathrm{C}$ e $28^{\circ} \mathrm{C}$ (TOCANTINS, 2012). A altitude registrada na área de estudo está situada entre as cotas de 250 a $300 \mathrm{~m}$. A topografia foi caracterizada por superfícies planas ou ligeiramente onduladas e os solos da área de estudo foram classificados em Latossolo Amarelo, Latossolo Amarelo, Plintossolo Pétrico, Latossolo Vermelho, Plintossolo, Plintossolo + Cambissolo e Gleissolo (EMBRAPA, 2013).

\section{Tratamento botânico}

O levantamento florístico foi realizado entre agosto de 2015 e setembro de 2016 com coletas quinzenais. Utilizou-se o método de parcela (MUELLER-DOMBOIS; ELLENBERG, 1974), em que foram alocadas, sistematicamente, cinco parcelas permanentes de $20 \times 50 \mathrm{~m}$, ou seja, $1.000 \mathrm{~m}^{2}$ cada, sendo que as mesmas foram distanciadas $10 \mathrm{~m}$ entre si. No interior das parcelas, foram amostrados todos os indivíduos 
arbustivo-arbóreos, com circunferência a 1,30 m do solo (CAP) maior ou igual a $10 \mathrm{~cm}$.

Os materiais botânicos das espécies amostradas foram herborizados seguindo as técnicas convencionais propostas por Fildalgo e Bononi (1984) e Mori et al. (1985). Posteriormente, foram identificados com o auxílio de lupa binocular, bibliografia especializada, consulta a especialistas e comparações com materiais depositados no Herbário do Tocantins (HTO), localizado na Universidade Federal do Tocantins - campus Porto Nacional.

As espécies foram classificadas com base no sistema de classificaçãoAPG IV(ANGIOSPERM PHYLOGENY GROUP, 2016). A grafia e autoria dos binômios específicos e sinonímias foram confirmadas nas bases de dados "Lista de Espécies da Flora do Brasil" (JARDIM BOTÂNICO DO RIO DE JANEIRO, 2016) e IPNI"International Plant Names Index" (INSTITUTO NACIONAL DA PROPRIEDADE INDUSTRIAL, 2016).

Para a elaboração da chave de identificação, foi realizada uma seleção dentre as espécies amostradas, considerando-se apenas as espécies que possuíam número de indivíduos maior ou igual a 5. Desta forma, foram selecionadas 54 espécies dentre as 106 amostradas. Cabe ressaltar que essa seleção das espécies teve como objetivo incluir apenas as espécies de maior recorrência no cerrado sensu stricto estudado com finalidade de viabilizar a funcionalidade da chave.

Para cada espécie selecionada, foram feitas descrições de 43 características dendrológicas importantes para a confecção da chave de identificação, sendo que essas descrições se basearam em anotações e observações do material botânico, realizadas em campo e em laboratório, com auxílio de um microscópio estereoscópico. Tais descrições foram utilizadas somente para elaboração da chave dendrológica e não constam no presente estudo.

Para as descrições das características vegetativas de cada espécie, consideraram-se as variações morfológicas dos exemplares coletados. As terminologias utilizadas para os caracteres vegetativos foram baseadas nas seguintes bibliografias: Marchiori (2004); Gonçalves e Lorenzi (2007); Silva Júnior et al. (2014).

A confecção da chave de identificação em nível específico foi baseada nas características morfológicas vegetativas que melhor distinguem os táxons. Por fim, ilustrações das características utilizadas na chave dendrológica foram realizadas com o auxílio de uma câmara clara acoplada ao microscópio estereoscópico.

\section{Resultados e Discussão}

Foram amostradas 106 espécies, entretanto, foram incluídas na chave apenas os táxons que possuíam número de indivíduos maior ou igual a cinco, desta forma, foram selecionados 54 espécies. Ressaltando-se que essa seleção teve como objetivo incluir apenas as espécies de maior recorrência no cerrado sensu stricto estudado com a finalidade de viabilizar a funcionalidade da chave.

A chave de identificação baseada em caracteres vegetativos foi composta por 54 espécies arbustivoarbóreas de eudicotiledôneas e angiospermas basais, distribuídas em 47 gêneros, incluídos em 26 famílias botânicas. A confecção da chave de identificação dendrológica demonstrou-se uma ferramenta funcional, ou seja, permitiu uma rápida e fácil identificação das espécies vegetais amostradas (Tabela 1).

\section{Tabela 1 - Famílias e espécies amostradas na área de cerrado sensu stricto, Gurupi - TO, incluí- das na chave de identificação sendo as mesmas ordenadas alfabeticamente por família.}

Table 1 - Families and species sampled in the cerrado sensu stricto area, Gurupi -TO state, included in the identification key and ranked alphabetically by family.

\begin{tabular}{lccc}
\hline Família/ Espécie & Nome Popular & Coletor/ número de coletor & Voucher \\
\hline ANACARDIACEAE & & & HTO 11.237 \\
1. Astronium fraxinifolium Schott & gonçalo-alves & J.B. Cândido \& G.O. Silva, 191 & HTO 11.238 \\
2. Myracrodruon urundeuva & allemão & J.B. Cândido et al., 205 & HTO 11.239 \\
3. Tapirira guianensis Aubl. & pombeiro & J.B. Cândido et al., 206
\end{tabular}


Tabela 1 - Continuação...

Table 1 - Continued...

\begin{tabular}{|c|c|c|c|}
\hline Família/ Espécie & Nome Popular & Coletor/ número de coletor & Voucher \\
\hline \multicolumn{4}{|l|}{ ANNONACEAE } \\
\hline 4. Annona crassiflora Mart. & araticum & $\begin{array}{l}\text { J.B. Cândido \& G.O. Silva, 192, J.B. } \\
\text { Cândido et al., 214, } 219\end{array}$ & HTO 11.240 \\
\hline 5. Xylopia aromatica (Lam.) Mart. & pimenta-de-macaco & J.B. Cândido et al., 198 & HTO 11.241 \\
\hline \multicolumn{4}{|l|}{ APOCYNACEAE } \\
\hline $\begin{array}{l}\text { 6. Aspidosperma subincanum } \\
\text { Mart. }\end{array}$ & guatambu & J.B. Cândido \& I. Morais, 242 & HTO 11.242 \\
\hline \multicolumn{4}{|l|}{ BIGNONIACEAE } \\
\hline $\begin{array}{l}\text { 7. Handroanthus impetiginosus } \\
\text { (Mart. ex DC.) Mattos }\end{array}$ & ipê-roxo & J.B. Cândido et al., 217 & HTO 11.209 \\
\hline $\begin{array}{l}\text { 8. Tabebuia roseoalba (Ridl.) } \\
\text { Sandwith }\end{array}$ & ipê-branco & J.B. Cândido \& I. Morais, 247 & HTO 11.210 \\
\hline \multicolumn{4}{|l|}{ BURSERACEAE } \\
\hline $\begin{array}{l}\text { 9. Protium heptaphyllum (Aubl.) } \\
\text { Marchand }\end{array}$ & almecegueira & J.B. Cândido et al., 199 & HTO 11.211 \\
\hline \multicolumn{4}{|l|}{ CHRYSOBALANACEAE } \\
\hline 10. Hirtella ciliata Mart. \& Zucc. & pau-pombo & J.B. Cândido et al., 223 & HTO 11.212 \\
\hline 11. Hirtella glandulosa Spreng. & vermelhão & J.B. Cândido et al., 194 & HTO 11.213 \\
\hline \multirow{2}{*}{\multicolumn{4}{|c|}{$\begin{array}{l}\text { 12. Hirtella hebeclada Moric. } \\
\text { DC. } \\
\text { COMBRETACEAE }\end{array}$}} \\
\hline & & & \\
\hline 13. Terminalia argentea Mart. & capitão-do-campo & J.B. Cândido et al., 198 & HTO 11.215 \\
\hline DILLENIACEAE & & & \\
\hline 14. Curatella americana $\mathrm{L}$. & sambaíba & J.B. Cândido \& I. Morais, 243 & HTO 11.216 \\
\hline \multicolumn{4}{|l|}{ EBENACEAE } \\
\hline 15. Diospyros hispida A.DC. & olho-de-boi & J.B. Cândido et al., 204 & HTO 11.217 \\
\hline \multicolumn{4}{|l|}{ FABACEAE } \\
\hline $\begin{array}{l}\text { 16. Anadenanthera peregrina (L.) } \\
\text { Speg. }\end{array}$ & angico-vermelho & J.B. Cândido \& I. Morais, 245 & HTO 11.218 \\
\hline 17. Copaifera langsdorffii Desf. & copaíba & J.B. Cândido et al., 200 & HTO 11.219 \\
\hline 18. Hymenaea courbaril $\mathrm{L}$. & jatobá-da-mata & J.B. Cândido et al., 222 & HTO 11.220 \\
\hline 19. Machaerium brasiliense Vogel & pau-sangue & J.B. Cândido \& I. Morais, 244 & HTO 11.221 \\
\hline 20. Platypodium elegans Vogel & amendoim-do-campo & J.B. Cândido et al., 240 & HTO 11.222 \\
\hline 21. Tachigali aurea Tul. & pau-bosta & J.B. Cândido et al., 216 & HTO 11.223 \\
\hline $\begin{array}{l}\text { 22. Vatairea macrocarpa (Benth.) } \\
\text { Ducke }\end{array}$ & amargoso & J.B. Cândido et al., 210 & HTO 11.224 \\
\hline \multicolumn{4}{|l|}{ ICACINACEAE } \\
\hline 23. Emmotum nitens (Benth.) Miers & araçá-do-mato & J.B. Cândido et al., 201, 215 & HTO 11.225 \\
\hline \multicolumn{4}{|l|}{ LAURACEAE } \\
\hline 24. Persea willdenovii Kosterm. & abacateiro-da-mata & J.B. Cândido et al., 193 & HTO 11.226 \\
\hline \multicolumn{4}{|l|}{ LOGANIACEAE } \\
\hline 25. Antonia ovata Pohl & redondinha & J.B. Cândido \& G.O. Silva, 190 & HTO 11.227 \\
\hline
\end{tabular}


Tabela 1 - Continuação...

Table 1 - Continued...

\begin{tabular}{|c|c|c|c|}
\hline Família/ Espécie & Nome Popular & Coletor/ número de coletor & Voucher \\
\hline \multicolumn{4}{|l|}{ MALPIGHIACEAE } \\
\hline 26. Byrsonima basiloba A.Juss. & murici-do-campo & J.B. Cândido et al., 237 & HTO 11.228 \\
\hline 27. Byrsonima pachyphylla A.Juss. & murici & J.B. Cândido et al., 220 & HTO 11.229 \\
\hline 28. Byrsonima stipulacea A.Juss. & murici-da-mata & J.B. Cândido et al., 225 & HTO 11.230 \\
\hline \multicolumn{4}{|l|}{ MALVACEAE } \\
\hline 29. Apeiba tibourbou Aubl. & pente-de-macaco & J.B. Cândido et al., 233 & HTO 11.231 \\
\hline $\begin{array}{l}\text { 30. Eriotheca pentaphylla (Vell. \& } \\
\text { K.Schum.) A.Robyns }\end{array}$ & embiruçu & J.B. Cândido et al., 221 & HTO 11.232 \\
\hline $\begin{array}{l}\text { 31. Luehea grandiflora Mart. \& } \\
\text { Zucc. }\end{array}$ & açoita-cavalo & J.B. Cândido et al., 238 & HTO 11.233 \\
\hline $\begin{array}{l}\text { 32. Pseudobombax longiflorum } \\
\text { (Mart. \& Zucc.) A.Robyns }\end{array}$ & mamonarana & J.B. Cândido et al., 232 & HTO 11.234 \\
\hline \multicolumn{4}{|l|}{ MYRISTICACEAE } \\
\hline 33. Virola sebifera Aubl. & ucuúba-vermelha & J.B. Cândido et al., 229 & HTO 11.235 \\
\hline \multicolumn{4}{|l|}{ MYRTACEAE } \\
\hline $\begin{array}{l}\text { 34. Calyptranthes clusiifolia } \\
\text { O.Berg }\end{array}$ & araçarana & J.B. Cândido et al., 234 & HTO 11.236 \\
\hline 35. Myrcia splendens (Sw.) DC. & araçá-do-mato & J.B. Cândido et al., 23 & HTO 11.197 \\
\hline 36. Myrcia tomentosa (Aubl.) DC. & goiaba-brava & J.B. Cândido et al., 224 & HTO 11.198 \\
\hline \multicolumn{4}{|l|}{ NYCTAGINACEAE } \\
\hline 37. Guapira opposita (Vell.) Reitz & maria-mole & J.B. Cândido et al., 212 & HTO 11.199 \\
\hline \multicolumn{4}{|l|}{ POLYGONACEAE } \\
\hline 38. Coccoloba mollis Casar. & folha-de-lobo & J.B. Cândido et al., 211 & HTO 11.200 \\
\hline \multicolumn{4}{|l|}{ PROTEACEAE } \\
\hline 39. Roupala montana Aubl. & carne-de-vaca & J.B. Cândido et al., 231 & HTO 11.201 \\
\hline \multicolumn{4}{|l|}{ RUBIACEAE } \\
\hline 40. Cordiera sessilis (Vell.) Kuntze. & marmelinho-do-campo & J.B. Cândido et al., 227 & HTO 11.202 \\
\hline 41. Amaioua guianensis Aubl. & marmelada-brava & $\begin{array}{l}\text { J.B. Cândido et al., 203; J.B. Cândido } \\
\text { \& I. Morais, } 241\end{array}$ & HTO 11.203 \\
\hline $\begin{array}{l}\text { 42. Coussarea hydrangeifolia } \\
\text { (Benth.) Müll.Arg. }\end{array}$ & falsa-quina & J.B. Cândido et al., 235 & HTO 11.204 \\
\hline $\begin{array}{l}\text { 43. Guettarda viburnoides Cham. } \\
\text { \& Schltdl. }\end{array}$ & veludo-branco & J.B. Cândido et al., 239 & HTO 11.205 \\
\hline 44. Palicourea rigida Kunth & chapéu-de-couro & J.B. Cândido et al., 209 & HTO 11.206 \\
\hline 45. Psychotria carthagenensis Jacq. & cafezinho & J.B. Cândido et al., 226 & HTO 11.207 \\
\hline \multicolumn{4}{|l|}{ RUTACEAE } \\
\hline 46. Zanthoxylum rhoifolium Lam. & mamica-de-porca & J.B. Cândido \& I. Morais, 248 & HTO 11.208 \\
\hline \multicolumn{4}{|l|}{ SALICACEAE } \\
\hline 47. Casearia sylvestris $\mathrm{Sw}$. & cafezinho-do-mato & J.B. Cândido et al., 230 & HTO 11.189 \\
\hline \multicolumn{4}{|l|}{ SAPINDACEAE } \\
\hline 48. Dilodendron bipinnatum Radlk. & mulher-pobre & J.B. Cândido et al., 213, 249 & НTO 11.190 \\
\hline 49. Magonia pubescens A.St.-Hil. & tingui & J.B. Cândido et al., 208 & HTO 11.191 \\
\hline
\end{tabular}


Tabela 1 - Conclusão...

Table 1 - Conclusion...

\begin{tabular}{llll}
\hline Família/ Espécie & Nome Popular & Coletor/ número de coletor & Voucher \\
\hline $\begin{array}{l}\text { SAPOTACEAE } \\
\text { 50. Pouteria ramiflora } \text { (Mart.) } \\
\quad \text { Radlk. }\end{array}$ & grão-de-galo & J.B. Cândido et al., 228 & HTO 11.192 \\
\hline $\begin{array}{l}\text { VOCHYSIACEAE } \\
\text { 51. Callisthene major Mart. }\end{array}$ & pau-terra-do-mato & J.B. Cândido et al., 195 & HTO 11.193 \\
52. Qualea grandiflora Mart. & pau-terra-grande & J.B. Cândido et al., 196 & HTO 11.194 \\
53. Qualea multiflora Mart. & pau-terra-liso & J.B. Cândido et al., 202 & HTO 11.195 \\
54. Qualea parviflora Mart. & pau-terra-roxo & J.B. Cândido et al., 207 & HTO 11.196 \\
\hline
\end{tabular}

As famílias mais ricas em espécies foram Fabaceae (sete), Rubiaceae (seis), Malvaceae e Vochysiaceae (quatro), Anacardiaceae, Chrysobalanaceae, Malpighiaceae e Myrtaceae (3), Annonaceae, Bignoniaceae e Sapindaceae (2), as demais famílias contribuíram com apenas uma espécie cada. Os gêneros mais representativos foram Byrsonima Rich. ex Kunth, Hirtella L. e Qualea Aubl. (3) e Myrcia DC. (2). Os demais gêneros foram representados por apenas uma espécie cada.

\section{Chave de identificação para as espécies arbustiva-arbóreas com base em caracteres vegetativos}

1. Folhas compostas ou recompostas

2. Folhas recompostas

3. Tronco fissurado, com grande quantidade de acúleos, casca interna parda a alaranjada; ramos não lenticelados; glândulas vináceas ao longo da raque; folíolo com 88 a 152 foliólulos, terminal não rudimentar, lanceolados, margem inteira, venação hifódroma (Figura $2 \mathrm{G}$ ) 16. Anadenanthera peregrina 3'. Tronco rugoso, inerme, casca interna rosada a avermelhada; ramos densamente lenticelados; glândulas ausentes ao longo da raque; folíolo com 13 a 17 foliólulos, terminal rudimentar, estreito-ovais, margem dentada, venação camptódroma (Figura 2C). 48. Dilodendron bipinnatum

2'. Folhas compostas

4. Folhas digitadas

5. Tronco liso, estriado; folíolos obovados, margem inteira, venação craspedódroma ou broquidródoma 6. Tronco esverdeado com estrias alvas, base reta, ramos sem embira; raque 40-43 cm compr., folíolos 33-30 × 17-16 cm, não articulados, face adaxial estrigosa, face abaxial pubescente, venação craspedódroma ..............................................................................32. Pseudobombax longiflorum 6'. Tronco marrom com estrias de mesma coloração, base digitada, ramos com embira; raque 16-17 cm compr., folíolos 18-12 × 9-5 cm, articulados, ambas as faces glabras, venação broquidódroma (Figura 2B) 30. Eriotheca pentaphylla

5'. Tronco levemente fissurado, não estriado; folíolos elípticos, margem repanda, venação camptódroma 07. Handroanthus impetiginosus

4'. Folhas penadas

7. Folhas paripenadas

8. Tronco fissurado; ramos lenticelados

9. Tronco com casca interna vinácea; ramos com lenticelas castanhas; estípulas ausentes, raque até $11 \mathrm{~cm}$ compr., folhas com 8 folíolos, elípticos a ovais, concolores, glabros em ambas as faces, pontuações translúcidas presente, venação cladódroma (Figura 2D) ........ 17. Copaifera langsdorffii 9'. Tronco com casca interna creme; ramos com lenticelas brancas; estípulas axilares, raque 11-17 cm compr., folhas com 10 a 14 folíolos, oblongos, discolores, pubescente em ambas as faces, pontuações translúcidas ausentes, venação eucamptódroma

20. Platypodium elegans

8'. Tronco estriado a reticulado ou rugoso; ramos sem lenticelas

10. Tronco estriado a reticulado; estípulas axilares, raque $2-7,5 \mathrm{~cm}$ compr., bifolíoladas, folíolos, elípticos a assimétricos, base assimétrica, com pontuações translúcidas, venação broquidódroma

18. Hymenaea courbaril

10'. Tronco rugoso; estípulas ausentes, raque 6,5-35 cm compr., folhas com 8 a 14 folíolos, ovais a lanceolados, base arredondada, sem pontuações translúcidas, venação camptódroma 
7'. Folhas imparipenadas

11. Folhas trifolioladas

08. Tabebuia roseoalba

11'. Folhas nunca trifolioladas

12. Folíolos elípticos a estreito-elípticos, margem serreada, venação craspedódroma, com odor agradável semelhante à manga

13. Tronco fissurado, ritidoma com desprendimento em placas lenhosas; ramos não lenticelados; gemas axilares arredondadas, vermelhas; folíolos 15,5-9 × 7-4,5 cm, ápice acuminado, base obtusa a arredondada, concolores, velutinas em ambas as faces (Figura $3 \mathrm{H}$ )

01. Astronium fraxinifolium

13'. Tronco rugoso, ritidoma indeiscente; ramos densamente lenticelados; gemas axilares deltoides, castanhas; folíolos 8,5-6,7 × 3,2-1,8 cm, ápice cuneado, base assimétrica, levemente discolor, estrigosa na face adaxial, pubescente na face abaxial (Figura 3I) 02. Myracrodruon urundeuva

12'. Folíolos ovais, lanceolados ou oblongos, margem inteira ou crenada, venação broquidódroma, sem odor agradável semelhante à manga

14. Tronco com acúleos mameliformes; glândulas foliares de secreção castanha, acúleos na nervura primária, margem crenada, pontuações translúcidas na lâmina foliar e nas margens, entre as crenas (Figura 3M)

46. Zanthoxylum rhoifolium 14'. Tronco sem acúleos; glândulas foliares ausentes, acúleos ausentes, margem inteira, pontuações translúcidas ausentes

15. Tronco com exsudações

16. Tronco tortuoso, fissurado, ritidoma com deiscência em lâminas, casca interna sem odor característico, com estrias vermelho-sangue, exsudações do tipo goma, vermelho-sangue; peciólulo cilíndrico, raque 13-29 cm compr., folíolo terminal rudimentar, base subcordada

19. Machaerium brasiliense 16'. Tronco cilíndrico, rugoso, ritidoma indeiscente, casca interna com odor agradável semelhante a incenso, sem estrias, exsudações do tipo resina, hialina ou branca ao cristalizar; peciólulo halteriforme, raque $5-14,5 \mathrm{~cm}$ compr., folíolo terminal não rudimentar, base cuneada ou assimétrica (Figura 4Q)

09. Protium heptaphyllum

15'. Tronco sem exsudações

17. Tronco rugoso, base reta, desprendimento em placas lenhosas circulares, permanecendo as cicatrizes; folíolos 9 a 11, folíolo terminal rudimentar, base obtusa, nervura primária saliente em ambas as faces (Figura 40)

49. Magonia pubescens 17'. Tronco estriado ou fissurado, base dilatada, indeiscente ou com desprendimento em placas lenhosas retangulares, sem cicatrizes; folíolos 7 a 9 , folíolo terminal não rudimentar, base assimétrica ou subcordada, nervuras não salientes ou somente na face abaxial

18. Tronco estriado, indeiscente; gemas axilares lanceoladas, adnatas aos ramos, raque glabra, folíolos 19-9 × 5,6-4 cm, lanceolados, base assimétrica, nervuras primárias e secundárias salientes na face abaxial (Figura 3J) 03. Tapirira guianensis

18'. Tronco fissurado, desprendimento em placas lenhosas retangulares; gemas axilares deltoides a ovais, não adnatas aos ramos, raque com tricomas alvos, folíolos 9-3,4 × 5-2,8 cm, oblongos ou ovados, base subcordada, nervuras primárias e secundárias não salientes em nenhuma das faces

22. Vatairea macrocarpa

1'. Folhas simples

19. Folhas de filotaxia oposta ou verticiladas

20. Folhas com estípulas

21. Ramos de crescimento modular (Figura 4R); folhas com a face abaxial densamente velutina, pecíolo achatado ao menos em uma das faces, pubescente

22. Tronco de base dilatada, casca interna rósea; folhas lanceoladas, ápice atenuado, glabra na face adaxial, pecíolo achatado na face adaxial

26. Byrsonima basiloba

22'. Tronco de base digitada, casca interna alaranjada ou avermelhada; folhas elípticas a largo-elípticas ou obovadas, ápice cuneado, obtuso ou arredondado, com pilosidade na face adaxial, pecíolo achatado em ambas as faces

23. Ramos castanho-avermelhados; casca interna alaranjada; folhas com face adaxial velutina, pecíolo até $0,6 \mathrm{~cm}$ compr. 
23'. Ramos castanho-amarelados; casca interna avermelhada; folhas com face adaxial levemente pubescente, pecíolo até $1 \mathrm{~cm}$ compr.

28. Byrsonima stipulacea

21'. Ramos com crescimento não modular; folhas com face abaxial glabra ou pubescente, pecíolo ausente, quando presente, cilíndrico ou acanalado, sempre glabro

24. Tronco com base reta, não lenticelado; ramos amarelados, com crescimento dicotômico, nó e entrenó bem marcados

25. Tronco com ritidoma com desprendimento em placas lenhosas; ramos com crescimento dicotômico, sem nó e entrenó marcado; estípulas interpeciolares persistentes, folhas herbáceas, pecioladas $0,3-1 \mathrm{~cm}$ compr. ......................................................................... 40. Cordiera sessilis 25'. Tronco com ritidoma indeiscente; ramos sem crescimento dicotômico, com nó e entrenó bem marcados; estípulas interpeciolares caducas, folhas coriáceas, sésseis .

44. Palicourea rigida

24'. Tronco com base dilatada ou digitada, lenticelado; ramos acinzentados, sem crescimento dicotômico, nó e entrenó nunca marcados

26. Tronco de base dilatada, rugoso, ritidoma com desprendimento em placas lenhosas, casca interna rósea; folhas opostas cruzadas, suborbicular a largo-ovadas, face abaxial glabra, venação broquidódroma

42. Coussarea hydrangeifolia

26'. Tronco de base digitada, rugoso, ritidoma indeiscente, casca interna amarelada; folhas opostas dísticas, elípticas a largo-elípticas, face abaxial pubescente, venação camptódroma

45. Psychotria carthagenensis

20'. Folhas sem estípulas

27. Folhas com pontuações translúcidas

28. Tronco de base dilatada, ritidoma indeiscente; folhas com odor agradável semelhante à goiaba ao serem maceradas, fortemente caducas após herborização . 34. Calyptranthes clusiifolia 28'. Tronco de base digitada ou reta, ritidoma com desprendimento; folhas sem odor característico ao serem maceradas, persistentes após herborização

29. Tronco tortuoso, ritidoma reticulado, desprendimento em placas lenhosas, base digitada; folhas disposta ao longo dos ramos, glabras em ambas as faces ... 35. Myrcia splendens

29'. Tronco cilíndrico, ritidoma liso, desprendimento em esfoliações, base reta; folhas dispostas na região terminal dos ramos, pubescente em ambas as faces 36. Myrcia tomentosa

27’. Folhas sem pontuações translúcidas

30. Ramos com glândulas

31. Ramos lenticelados; glândulas axilares, triangulares, pubescentes, folhas sésseis (Figura 3K) 51. Callisthene major

31'. Ramos não lenticelados; glândulas interpeciolares, circulares, glabras, folhas pecioladas (Figura 3L)

32. Tronco de base digitada; ramos fissurados; folhas de até $8 \mathrm{~cm}$ de compr., ápice cuneado ou obtuso, face abaxial velutina .

54. Qualea parviflora

32'. Tronco de base reta; ramos lisos; folhas maiores que $8,5 \mathrm{~cm}$ de compr., ápice acuminado, face abaxial pubescente

33. Tronco reticulado com profundas fissuras, ritidoma com desprendimento em placas lenhosas; folhas de base subcordada, glabra na face adaxial, nervura primária acanalada, secundárias retas .

52. Qualea grandiflora

33'. Tronco rugoso, ritidoma com desprendimento farináceo; folhas de base truncada ou arredondada, pubescente na face adaxial, nervura primária não acanalada, secundárias curvadas no sentido ascendente .....

53. Qualea multiflora

30'. Ramos sem glândulas

34. Tronco com ritidoma de desprendimento em lâminas rígidas, lenticelas poucas, agrupadas; ramos foliares tricotômicos; folhas dispostas na região terminal dos ramos, ápice acuminado, base decorrente, venação camptódroma, pecíolo de até $1 \mathrm{~cm}$ compr. (Figura 4P)

41. Amaioua guianensis

34'. Tronco indeiscente ou com ritidoma de desprendimento em pequenas placas lenhosas, lenticelas em grandes quantidades, esparsas; ramos foliares não tricotômicos; folhas dispostas ao longo dos ramos, ápice atenuado ou cuneado, base obtusa ou atenuada, venação broquidódroma, pecíolo maior que $1 \mathrm{~cm}$ compr.

35. Tronco rugoso, ritidoma indeiscente, base digitada; folhas apresentam oxidação após serem amassadas in situ ou herborizadas, ápice atenuado, base obtusa, concolores, glabra na face adaxial 
35'. Tronco reticulado, ritidoma com desprendimento em pequenas placas lenhosas, base dilatada; folhas não apresentam oxidação após serem amassadas ou herborizadas, ápice cuneado, base atenuada, discolores, densamente pubescente na face adaxial 43. Guettarda viburnoides

19'. Folhas de filotaxia alterna

36. Folhas de filotaxia alterna espiraladas

37. Ramos lenticelados

38. Folhas com venação broquidódroma

39. Tronco fendilhado, base digitada, lenticelas ausentes; ramos sem nó e entrenó marcados; estípulas deltoides, folhas elípticas, ápice acuminado, base cuneada a obtusa, face abaxial glabra, margem serreada, concolores, com pontuações translúcidas alongadas 47. Casearia sylvestris

39'. Tronco estriado, base dilatada, lenticelas presentes em linhas verticais; ramos com nó e entrenó marcados; estípulas modificadas em ócrea, folhas subcordadas, ápice atenuado, base cordada ou subcordada, face abaxial pubescente, margem inteira, discolores, sem pontuações translúcidas (Figura 4T) 38. Coccoloba mollis

38'. Folhas com venação cladódroma ou craspedódroma

40. Tronco de base reta, reticulado, indeiscente; ramos dicotômicos e/ou tricotômicos; folhas congestas na região terminal, obovadas, ápice cuspidado, base atenuada, margem inteira, herbáceas, incano-tomentosa na face abaxial, venação cladódroma, exsudação do tipo látex branco no pecíolo 06. Aspidosperma subincanum 40'. Tronco de base digitada, fissurado, ritidoma com desprendimento em lâminas; ramos não tricotômicos; folhas disposta ao longo dos ramos, elípticas a largo-elípticas, ápice cuneado ou obtuso, base decorrente, margem sinuada ou serrada, rígido-coriáceas, glabra e escabrosa na face abaxial, venação craspedódroma, sem exsudações no pecíolo (Figura 2E)

37'. Ramos não lenticelados

41. Folhas congestas na região terminal dos ramos

42. Tronco indeiscente, casca interna amarelada, com exsudação do tipo látex branco; folhas oblanceoladas, ápice cuneado, glabra na face adaxial, margem levemente revoluta, com exsudação do tipo látex branco

50. Pouteria ramiflora

42'. Tronco com desprendimento do ritidoma escamoso, casca interna avermelhada, com linhas verticais amarelas, sem exsudação; folhas elípticas, ápice acuminado, levemente estrigosa na face adaxial, margem não revoluta e ondulada, sem exsudação

13. Terminalia argentea

41'. Folhas dispostas ao longo dos ramos

43. Tronco profundamente fissurado, indeiscente, base reta, casca interna rosada a avermelhada; ramos pubescentes com tricomas estrelados; folhas concolores, base arredondada, venação craspedódroma

04. Annona crassiflora 43'. Tronco reticulado ou estriado, ritidoma com desprendimento em placas lenhosas, base dilatada, casca interna alaranjada; ramos glabros ou velutinos sem tricomas estrelados; folhas discolores, base cuneada, venação broquidódroma ou camptódroma

44. Tronco reticulado, não lenticelado; ramos velutinos; estípulas presentes, margem revoluta, face abaxial densamente velutina, venação broquidódroma, pecíolo acanalado, densamente velutino 10. Hirtella ciliata 44'. Tronco estriado, lenticelado; ramos glabros; estípulas ausentes, margem plana, face abaxial glabra, venação camptódroma, pecíolo achatado, glabro 24. Persea willdenovii

36'. Folhas de filotaxia alterna dísticas

45. Folhas com estípulas

46. Tronco estriado

47. Tronco e ramos não lenticelados; folhas de ápice acuminado, base obtusa, margem plana, levemente discolores, pubescente em ambas as faces, pecíolo de até $0,5 \mathrm{~cm}$ compr. (Figura 4S)

11. Hirtella glandulosa

47'. Tronco e ramos lenticelados; folhas de ápice atenuado ou cuneado, base arredondada, margem revoluta, concolores, glabra em ambas as faces, pecíolo maior que $0,5 \mathrm{~cm}$ compr. 
46'. Tronco fendilhado ou reticulado

48. Tronco fendilhado, base digitada, com exsudação do tipo goma translúcida; ramos não lenticelados, densamente hirsuto-velutinos; folhas com estípulas interpeciolares, sem glândulas laminar, base subcordada, margem serrada, pubescente na face adaxial, densamente velutina na face abaxial, venação camptódroma

29. Apeiba tibourbou 48'. Tronco reticulado, base dilatada, sem exsudação; ramos densamente pontuados com lenticelas brancas, glabros; folhas com estípulas axilares, pontuações glandulares negras na lâmina, base cuneada, margem inteira, glabra em ambas as faces, venação craspedódroma

23. Emmotum nitens

45'. Folhas sem estípulas

49. Folhas de venação broquidódroma

50. Tronco tortuoso, rugoso, base digitada, lenticelado; ramos inflexíveis, sem embira; folhas com oxidação após herborização, adquirindo coloração enegrecida, largo-elípticas, ápice e base arredondados, herbáceas, face abaxial velutina, com tricomas ferrugíneos 15. Diospyros hispida

50'. Tronco cilíndrico, reticulado, base reta, não lenticelado; ramos flexíveis, com embira; folhas sem oxidação após herborização, lanceoladas, ápice agudo, base truncada ou subcordada, coriáceas, face abaxial pubescente, com tricomas alvos . 05. Xylopia aromatica

49'. Folhas de venação actinódroma, camptódroma ou eucamptódroma

51. Tronco estriado; ramos com pilosidades; folhas de margem inteira, venação eucamptódroma. 52. Tronco de base dilatada, exsudação hialina, aquosa; ramos tomentosos; folhas oblongas ou orbiculares, ápice e base arredondada ou obtusa, face adaxial pubescente, face abaxial esparso-pubescente (Figura 2F) 25. Antonia ovata 52'. Tronco de base digitada, sem exsudação; ramos puberulentos em tufos; folhas estreitoovadas ou elípticas, ápice atenuado, base retusa, face adaxial glabra, face abaxial com tricomas estrelados (Figura $3 \mathrm{~N}$ ) 33. Virola sebifera 51'. Tronco fendilhado ou reticulado; ramos glabros; folhas com margem serreada ou pinatifendida, dentada nas bordas superiores, venação actinódroma ou camptódroma

53. Tronco cilíndrico, fendilhado, ritidoma indeiscente, base dilatada, casca interna rósea, sem odor característico; folhas ovais, base assimétrica, margem serreada, face adaxial pubescente, face abaxial densamente velutina, venação actinódroma, pecíolo até $1 \mathrm{~cm}$ compr. (Figura 2A) 31. Luehea grandiflora

53'. Tronco semitortuoso, reticulado, ritidoma com desprendimento em placas lenhosas, base digitada, casca interna marrom-escura, com odor característico semelhante à carne cozida; folhas elípticas, base atenuada, margem pinatifendida, dentada nas bordas superiores, glabra em ambas as faces, venação camptódroma, pecíolo maior que $1 \mathrm{~cm}$ compr.

39. Roupala montana

A chave confeccionada pode auxiliar na identificação de algumas espécies com maior ocorrência no cerrado sensu stricto do sul-tocantinense ou de outras regiões com vegetação similar, dessa forma os pesquisadores e discentes da engenharia florestal e áreas afins, terão uma ferramenta para a realização de futuros trabalhos que exijam o conhecimento das espécies botânicas mais recorrentes nesse tipo vegetacional, como por exemplos trabalhos de: desenvolvimento de tecnologias de restauração florestal adaptadas à região; incentivo da produção de espécies botânicas nativas em viveiro, recuperação e manejo da área de estudo, assim como de áreas similares ou mesmo para conhecimento taxonômico das principais espécies ocorrentes.

É importante, porém, fazer algumas ressalvas com relação ao uso da chave elaborada. Os caracteres vegetativos podem variar muito de acordo com as características edafoclimáticas do local no qual a chave é utilizada. Além disso, deve-se ter atenção ao escolher o material a ser analisado, pois rebrotas, galhas, herbívora e doenças podem alterar as características morfológicas vegetativas do indivíduo, sendo preferível analisar ramos adultos e de plantas pouco avariadas para uma maior eficiência na sua utilização. Outro fator importante a se considerar são os caracteres morfológicos sazonais, como folhas e estípulas. Mesmo assim, para um melhor resultado na identificação, os caracteres utilizados são, na grande maioria, de fácil observação e que apresentam menos variação (como venação, filotaxia, glândulas e exsudações). Assim, esta chave dendrológica demonstrou ser uma ferramenta útil ao ser testada em campo, obtendo-se bons resultados na identificação. 
Figura 2 - Características vegetativas utilizadas na chave:

A: Luehea grandiflora - venação actinódroma. B: Eriotheca pentaphylla - venação broquidódroma. C: Dilodendron bipinnatum - venação camptódroma. D: Copaifera langsdorffii - venação cladódroma. E: Curatella americana - venação craspedódroma. F: Antonia ovata - venação eucamptódroma. G: Anadenanthera peregrina - venação hifódroma.

Figure 2 - Vegetative characteristics on the keys:

A: Luehea grandiflora - venation actinodromous. B: Eriotheca pentaphylla - venation brochidodromous. C: Dilodendron bipinnatum - venation camptodromous. D: Copaifera langsdorffii - venation cladodromous. E. Curatella americana - venation crapedodromous. F: Antonia ovata - venation eucamptodromous. G: Anadenanthera peregrina - venation hyphodromous.

A

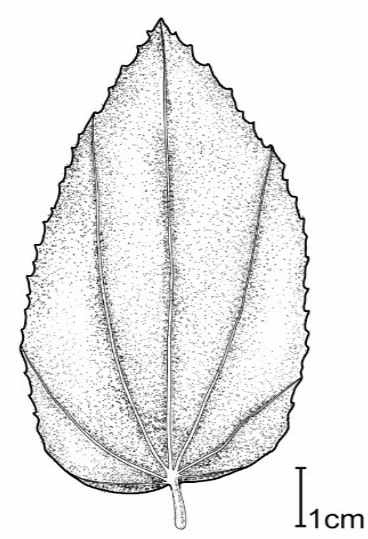

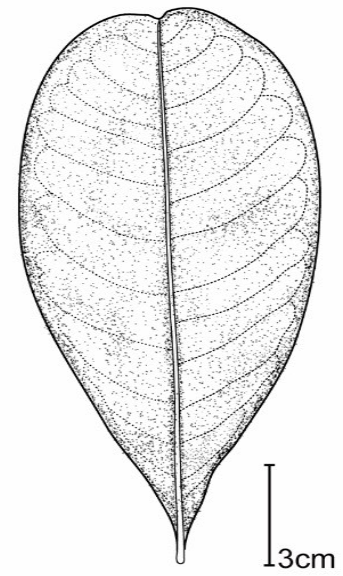
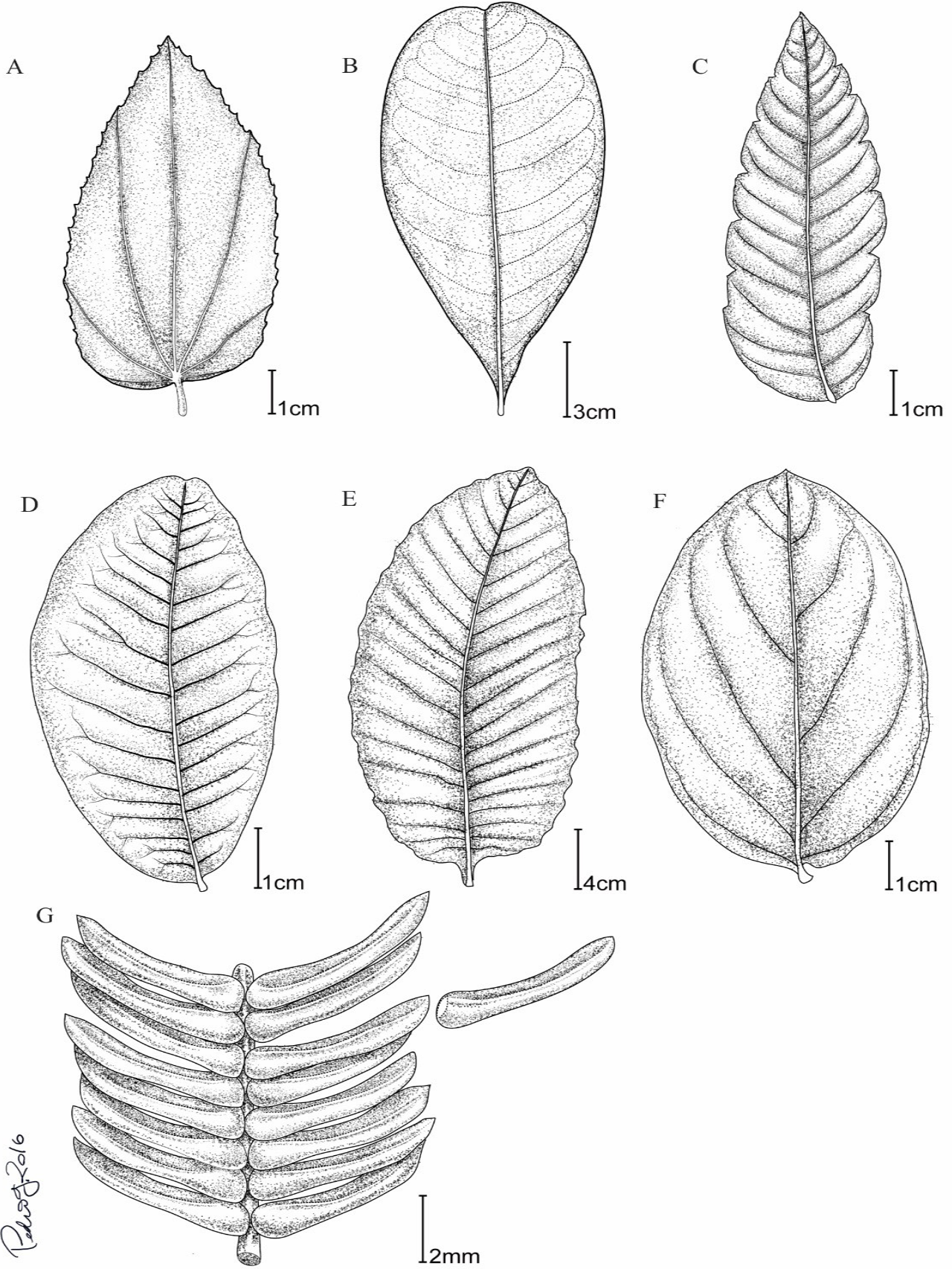
Figura 3 - Características vegetativas utilizadas na chave:

H: Astronium fraxinifolium - gemas axilares arredondadas. I: Myracrodruon urundeuva - gemas axilares deltoides. $\mathrm{J}$ : Tapirira guianensis - gemas axilares lanceoladas, adnatas aos ramos. $\mathrm{K}$ :

Callisthene major - glândulas axilares, triangulares, pubescente. L: Qualea parviflora - glândulas interpeciolares, circulares, glabras, sempre em par. M: Zanthoxylum rhoifolium - pontuações translúcidas na lâmina foliar e nas margens entre as crenas. N: Virola sebifera - face abaxial das folhas com tricomas estrelados.

Figure 3 - Vegetative characteristics on the keys:

$\mathrm{H}$ : Astronium fraxinifolium - rounded axillary bud. I: Myracrodruon urundeuva - deltoid axillary bud. $\mathrm{J}$ : Tapirira guianensis - lanceolate axillary bud adnate to the twigs. K: Callisthene major - axillary, triangular, pubescente gland. L: Qualea parviflora - interpetiolar, round, glabrous gland, always in pairs. M: Zanthoxylum rhoifolium - translucent dots in leaf blade and crenate. N: Virola sebifera - stellate trichomes on the abaxial side of the leaf.
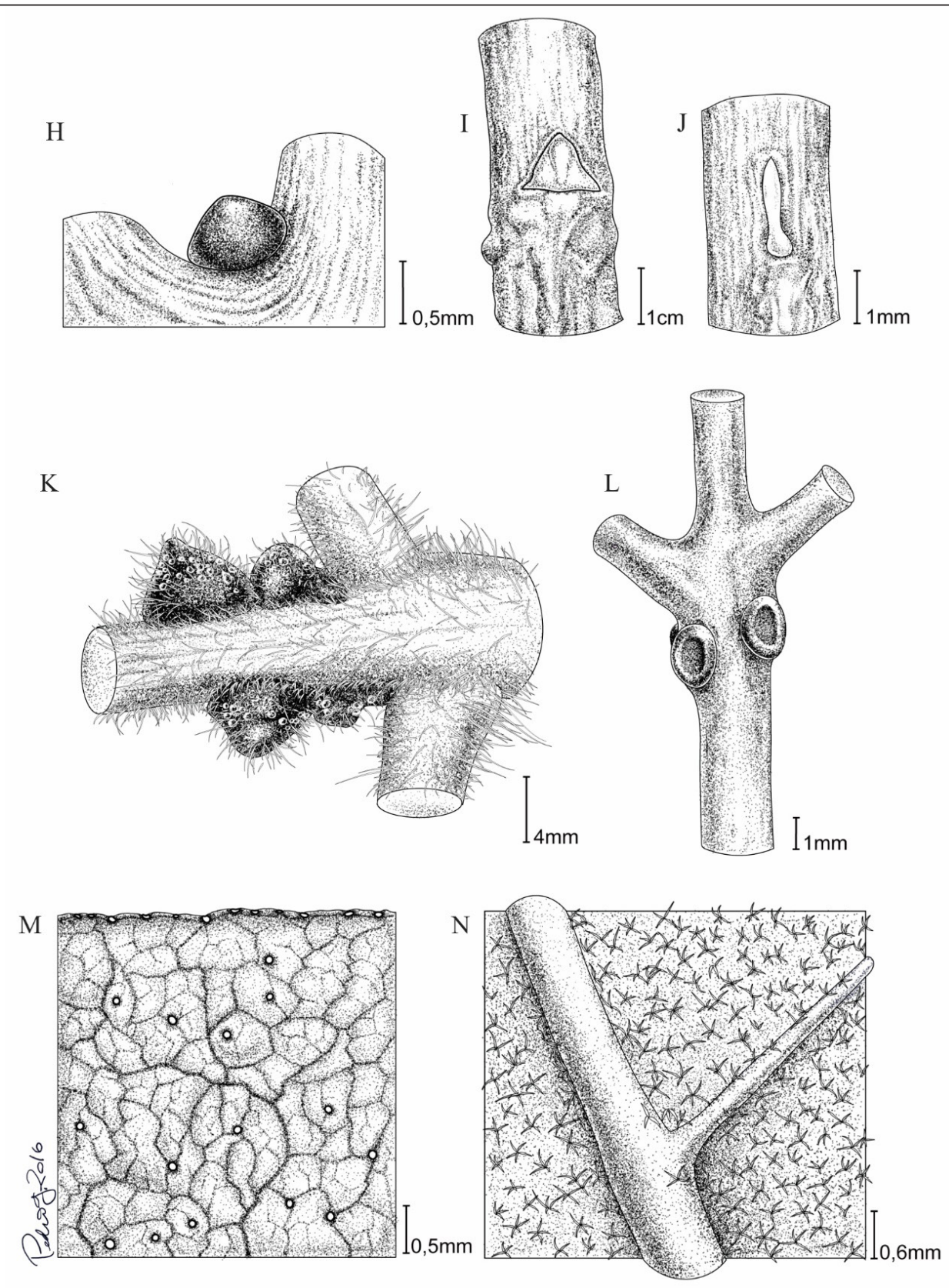
Figura 4 - Características vegetativas utilizadas na chave:

O: Magonia pubescens - folíolo terminal rudimentar. P: Amaioua guianensis - ramos foliares tricotômicos. Q: Protium heptaphyllum - peciólulo halteriforme. R: Byrsonima basiloba - ramos de crescimento modular. S: Hirtella glandulosa - folhas de ápice acuminado. T: Coccoloba mollis - estípulas modificadas em ócrea.

Figure 4 - Vegetative characteristics on the keys:

O: Magonia pubescens - rudimentary terminal leaflet. P: Amaioua guianensis - leaf twigs trichotomy. Q: Protium heptaphyllum - halteriform petiolule. R: Byrsonima basiloba - modular growing twigs. S: Hirtella glandulosa - acuminate apex leaves. T: Coccoloba mollis - stipule fused into ochrea.

$\mathrm{O}$
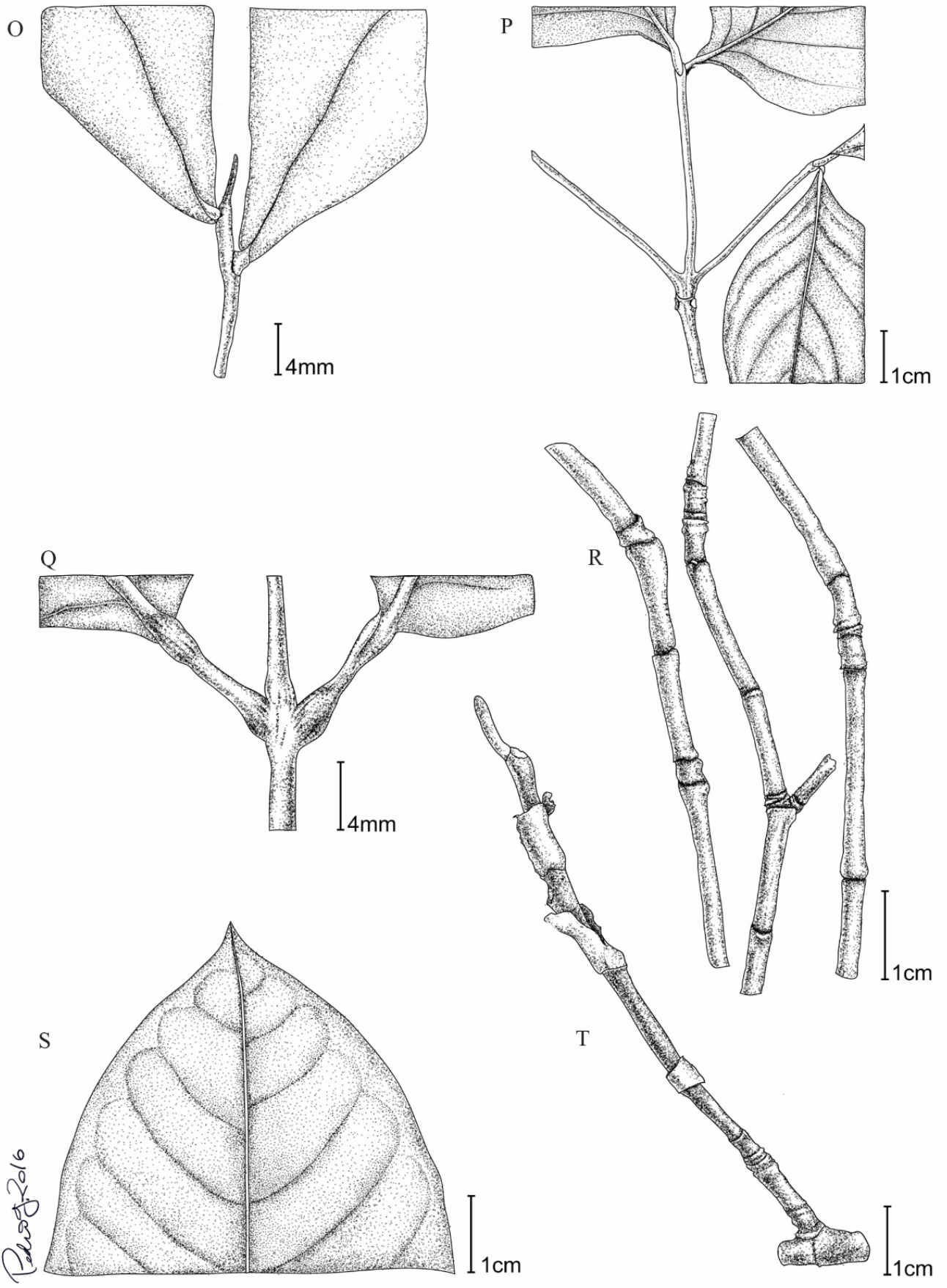

$\mathrm{P}$

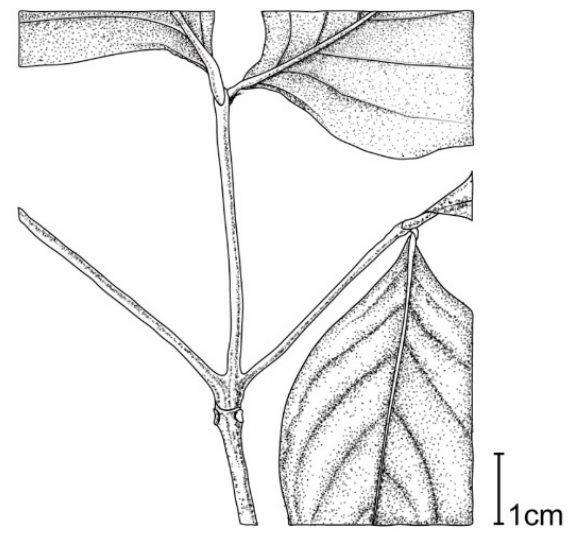

$11 \mathrm{~cm}$ 
A chave pode ser usada como suporte para a identificação de uma área de cerrado sensu stricto, com características vegetacionais semelhantes, todavia, devido à metodologia abordada utilizando apenas as espécies que possuíam número de indivíduos maior ou igual a cinco, ela não contribuirá de maneira efetiva na identificação das espécies raras, sendo interessante a realização de futuros trabalhos com as espécies raras da região.

\section{Conclusões}

A elaboração dessa chave dendrológica buscou contribuir para o conhecimento da flora do Cerrado tocantinense e subsidiar futuros estudos no desenvolvimento de tecnologias de restauração florestal no domínio, colaborando com ações de manejo e recuperação de áreas com características similares.

\section{Referências}

ANGIOSPERM PHYLOGENY GROUP. An update of the Angiosperm Phylogeny Group classification for the orders and families of flowering plants: APG IV. Botanical Journal of the Linnean Society, London, v. 181, p. 1-20, jan. 2016.

BRASIL. Ministério do Meio Ambiente. Mapeamento do uso e cobertura do cerrado: Projeto TerraClass Cerrado 2013. Brasília: MMA, 2015.

BRASIL. Ministério do Meio Ambiente. PPCerrado: Plano de Ação para prevenção e controle do desmatamento e das queimadas no Cerrado: $2^{a}$ fase (2014-2015). Brasília: MMA, 2014. 132 p.

BUTTLER, A. et al. Annual variation in soil respiration and its component parts in two structurally contrasting woody savannas in Central Brazil. Plant Soil, [S.1.], n. 352, p. 129-142, set. 2012.

EMBRAPA. Sistema brasileiro de classificação de solos. 3. ed. Rio de Janeiro: Centro Nacional de Pesquisas de Solos, 2013. 353 p.

FERREIRA, Q. S. F. et al. Fitossociologia e estrutura diamétrica de um cerrado sensu stricto, Gurupi -TO. Revista Verde de Agroecologia e Desenvolvimento Sustentável, Pombal, v. 10, n. 1, p. 229-235, jan./mar. 2015.

FERREIRA, R. Q. S. et al. Diversidade florística do estrato arbustivo arbóreo de três áreas de cerrado sensu stricto, Tocantins. Desafios, Tocantins, v. 4, n. 2, p. 69-82, maio 2017.

FIDALGO, O.; BONONI, V. L. R. Técnicas de coleta, preservação e herborização do material botânico. Instituto de Botânica. São Paulo: [s.n.], 1984. 61 p. (Manual 4).

GONÇALVES, E. G.; LORENZI, H. J. Morfologia vegetal: organografia e dicionário ilustrado de morfologia das plantas vasculares. Nova Odessa: Instituto Plantarum de Estudos da Flora, 2007.

HAIDAR, R. F. et al. Seasonal forests and ecotone areas in the state of Tocantins, Brazil: structure, classification and guidelines for conservation. Acta Amazonica, Manaus, v. 43, n. 3, p. 261-290, dez. 2013.

INSTITUTO NACIONAL DA PROPRIEDADE INDUSTRIAL (Brasil). The international plant names index. Search the data: plant names. Disponível em: http://www.ipni.org/ipni/plantnamesearchpage.do. Acesso em: 23 out. 2016.

JUDD, W. S. et al. Sistemática vegetal: um enfoque filogenético. 3. ed. Porto Alegre: Artmed, 2009.

LEMOS, H. L. et al. Structure and floristic relationships between Cerrado sensu stricto sites on two types of substrate in northern Cerrado, Brazil. Biota Neotropica, Campinas, v. 13, n. 4, p. 121-132, out./dez. 2013.

MARCHIORI, J. N. C. Elementos de dendrologia. 2. ed., Santa Maria: UFSM, 2004.

Ci. Fl., Santa Maria, v. 29, n. 1, p. 347-362, jan./mar., 2019 
MEDEIROS, M. B.; WALTER, M. L. Composição e estrutura de comunidades arbóreas de cerrado stricto sensu no norte do Tocantins e sul do Maranhão. Revista Árvore, Viçosa, MG, v. 36, n. 4, p. 673-683, jul./ago. 2012.

MENDONÇA, R. et al. Flora vascular do bioma Cerrado: checklist com 12.356 espécies. In: SANO, S. M.; ALMEIDA, S. P.; RIBEIRO, J. F. Cerrado: ecologia e flora. [S.1.]: EMBRAPA Informações Tecnológicas, 2008. v. 2. p. 287-556.

MORI, S. A. et al. Manual de manejo de Herbário fanerogâmico. Ilhéus: CEPLAC, 1985. 97 p.

MUELLER-DOMBOIS, D.; ELLENBERG, H. Aims and methods of vegetation ecology. New York: J. Wiley, 547 p, 1974.

PEDREIRA, F. R. B. et al. Composição florística e fitossociologia de espécies arbóreas em uma área de cerrado stricto sensu no Município de Porto Nacional, TO. Revista Global Science and Technology, Rio Verde, v. 4, n. 1, p. 08-15, abr. 2011.

PESTANA, L. T. C.; ALVES, F. M.; SARTORI, A. L. B. Espécies arbóreas da arborização urbana do centro do município de Campo Grande, Mato Grosso do Sul, Brasil. REVSBAU, Piracicaba, v. 6, n. 3, p. 1-21, set. 2011.

JARDIM BOTÂNICO DO RIO DE JANEIRO. REFLORA: Herbário virtual. Flora do Brasil 2020 em construção. Rio de Janeiro: Jardim Botânico do Rio de Janeiro, 2016. Disponível em: http://reflora.jbrj. gov.br/reflora/herbarioVirtual/. Acesso em: 23 out. 2016.

REJMANEK, M.; BREWER, S.W. 2001. Vegetative identification of tropical woody plants: state of the art and annotated bibliography. Biotropica 33: 214-228.

RIBEIRO, J. F.; WALTER, B. M. As Principais Fitofisionomias do Bioma Cerrado. In: SANO, S. M. et al. (Eds.). Cerrado: ecologia e flora. 1. ed. Brasília: Embrapa Informação Tecnológica, p. 151-212, 2008.

SANO, E. E.; ROSA, R.; BRITO, J. L. S.; FERREIRA, L. G. Mapeamento de cobertura vegetal do bioma Cerrado: estratégias e resultados. Embrapa Cerrado. Planaltina DF. 2007.

SANTOS, E. R.; LÓLIS, S. F. Análise florística em comunidades florestais nos Municípios de Caseara, Marianópolis, e Pium, no estado do Tocantins. Revista Carbono Social, Tocantins, v. 1, n. 2, p. 24-31, abr. 2007.

SILVA JÚNIOR, M. C. 100 árvores do cerrado: sentido restrito. 1. ed. Brasília: Rede de sementes do cerrado, 2012.

SILVA JÚNIOR, M. C. et al. Guia do observador de árvores: tronco, copa e folha. 1. ed. Brasília: Rede de sementes do cerrado, 2014.

SILVA JÚNIOR, M. C.; PEREIRA B. A. S. 100 árvores do cerrado: mata de galeria. 1. ed. Brasília: Rede de sementes do cerrado, 2009.

TEIXEIRA, C. Chave de identificação baseada em caracteres vegetativos para a arborização urbana de Foz do Iguaçu-PR. 2015. Monografia (Especialista na Pós-Graduação em Gestão Ambiental em Municípios) - Universidade Tecnológica Federal do Paraná, Curitiba, 2015.

TOCANTINS. Secretaria do Planejamento, Governança e Gestão. Atlas do Tocantins: subsídios ao planejamento da gestão territorial. Palmas: SEPLAN, 2012. (Palmas - Atual, 6).

URBANETZ, C.; TAMASHIRO, J. Y.; KINOSHITA, L. S. Chave de identificação de espécies lenhosas de um trecho de Floresta Ombrófila Densa Atlântica, no Sudeste do Brasil, baseada em caracteres vegetativos. Biota Neotropica, Campinas, v. 10, n. 2, p. 349-398, 2010. 